УДК 539.23

\title{
ОСОБЕННОСТИ ФОРМИРОВАНИЯ ТОНКИХ СЛОЕВ ДИСУЛЬФИДА МОЛИБДЕНА MOS, НА МЕТАЛЛИЧЕСКОМ МОЛИБДЕНЕ ПРИ РАЗНЫХ ТЕМПЕРАТУРАХ
}

\author{
(C) 2018 Э. П. Домашевская, С. А. Ивков, Аль Хайлани Хасан Исмаил Дамбос, \\ Радам Али Обайд Радам, С. В. Рябцев \\ Воронежский государственный университет, Университетская пл. 1, 394018 Воронеж, Россия \\ e-mail:ftt@phys.vsu.ru
}

Поступила в редакцию 02.02.2018

\begin{abstract}
Аннотация. В работе изучено влияние температуры на фазовый состав тонких слоев, образующихся на металлических пластинах молибдена при переносе паров серы газом-носителем аргоном из низкотемпературной в высокотемпературную зону реактора (двухтемпературный синтез). Результаты исследования методами рентгеновской дифракции и сканирующей электронной микроскопии образцов дисульфидов молибдена $\mathrm{MoS}_{2}$, полученных на металлических пластинах молибдена при различных температурах, показывают, что при высоких температурах синтеза в интервале $800-1000{ }^{\circ} \mathrm{C}$ на пластинах молибдена образуются дисульфиды молибдена разных модификаций/политипов: гексагональной $\mathrm{P} 6_{3} / \mathrm{mmc}$ при $800{ }^{\circ} \mathrm{C}$ и ромбоэдрической (тригональной) R3m при $1000^{\circ} \mathrm{C}$. При температуре $1000{ }^{\circ} \mathrm{C}$ происходит формирование микрокристаллов $\mathrm{MoS}_{2}$ с огранкой, соответствующей ромбоэдрической фазе $\mathrm{R} 3 \mathrm{~m}$.
\end{abstract}

Ключевые слова: двухтемпературный синтез, металлический молибден, дисульфид молибдена, политипы, гексагональная модификация, ромбоэдрическая модификация.

DOI: https://doi.org/10.17308/kcmf.2018.20/477

\section{ВВЕДЕНИЕ}

Дихалькогениды переходных металлов кристаллизуются в виде слоистых структур $[1,2]$. Этот класс соединений очень интересен из-за разнообразных свойств: квазидвумерные структуры широкого диапазона электрических свойств, начиная от полупроводникового и через металлическое к сверхпроводящему состоянию при достаточно низкой температуре; а также способности некоторых из этих соединений к интеркалированию. Большинство сульфидов металлов, в том числе $\mathrm{MoS}_{2}$, используются в оптоэлектронике при изготовлении солнечных элементов (СЭ) $[1,2]$. Из-за сильных взаимодействий между $d$-электронами атомов переходных металлов, $d$ - состояния молибдена расщепляются на две полосы, из которых нижняя энергетическая $d$-зона в основном имеет характер $d z^{2}$. Является ли данный материал полупроводником или металлом, зависит от степени заполнения этой полосы $d z^{2}$. Соединение $\mathrm{MoS}_{2}$ является полупроводником, потому что его $d z^{2}$ зона полностью заполнена.
Это соединение, как и другие дихалькогениды молибдена и вольфрама, кристаллизуется в слоистой структуре, такой, что атомы халькогена расположены в плотноупакованных гексагональных слоях, а атомы переходных металлов имеют шестикратную тригональную призматическую координацию. Существует два политипа: $2 \mathrm{H}$ и $3 \mathrm{R}$, из-за разных последовательностей в расположении слоев $[3,4]$. Политип $2 \mathrm{H}$ имеет два слоя в элементарной ячейке, уложенной в гексагональной симметрии в последовательности $\mathrm{AbA} / \mathrm{BaB}$ в сечении [1120] и принадлежит к пространственной группе $\mathrm{P} 6_{3} / \mathrm{mmc}$ $\left(\mathrm{D}_{6 \mathrm{~h}}^{4}\right)$. Верхний регистр последовательности букв обозначает атомы халькогена, буквы нижнего регистра используются для атомов переходных металлов, и знак / обозначает силы Ван-дер-Ваальса между двумя слоями атомов халькогена, рис. 1.

Политип R3m (3R) имеет три слоя в элементарной ячейке в направлении параметра $c$ (направление [0001]) в ромбоэдрической симметрии с последовательностью $\mathrm{AbA} / \mathrm{BcB} / \mathrm{CaC}$ в сечении [1120] и принадлежит к пространственной группе $\mathrm{R} 3 \mathrm{~m}$ 

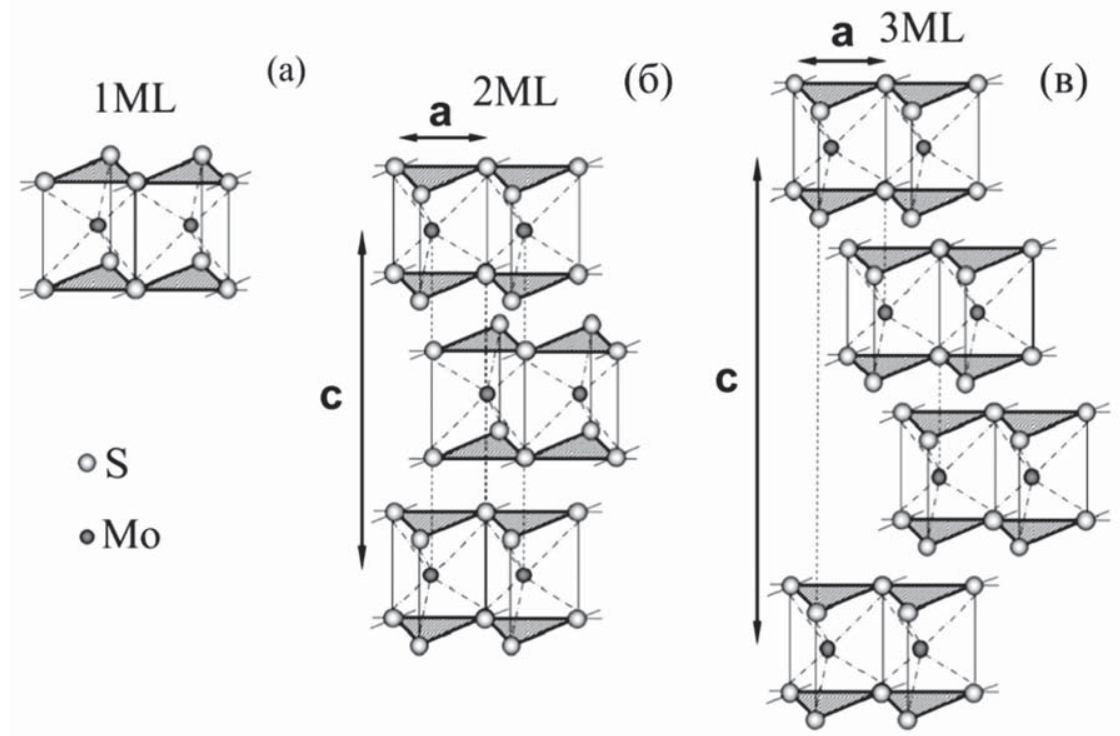

Рис. 1. Схематическое представление структуры $\operatorname{MoS}_{2}$ : монослой $(a), 2$ Н-политип (b) гекагональной структуры и 3R-политип (c) ромбоэдрической структуры объемных дисульфидов молибдена [3]

[Fig. 1. Schematic representation of the structure of $\mathrm{MoS}_{2}$ : monolayer $(a), 2 \mathrm{H}$-polytype hexagonal structure $(b)$ and 3Rpolytype rhombohedral structure $(c)$ of bulk molybdenum disulphides [3]]

$\left(\mathrm{C}_{3 \mathrm{v}}{ }^{5}\right)$. Поверхность кристаллов, перпендикулярная к параметру $c$, обычно называется поверхностью Ван-дер-Ваальса. Сильная анизотропия кристаллической структуры этих соединений приводит к легкому расщеплению слоев по плоскостям спайности, перпендикулярных к параметру с кристалла. Поэтому и физические свойства этих соединений должны быть очень анизотропными. Толщина одного молекулярного слоя $\mathrm{MoS}_{2}$ равна $6.25 \AA$.

Целью настоящей работы было показать влияние температуры газотранспортного синтеза на кристаллическую структуру слоев дисульфида молибдена $\mathrm{MoS}_{2}$, сформированных на пластинах металлического молибдена.

\section{МЕТОДИКА ПОЛУЧЕНИЯ ДИСУЛЬФИДОВ МОЛИБДЕНА $\mathrm{MoS}_{2}$}

Дисульфид молибдена получали в экспериментальной установке, которая состояла из герметизированной кварцевой трубы, средняя часть которой нагревалась до необходимых температур 300$1000{ }^{\circ} \mathrm{C}$ с помощью электрической печи. В средней высокотемпературной части кварцевой трубы размещалась молибденовая фольга, предварительно очищенная от окислов в соляной кислоте и затем промытая в дистиллированной воде. Через герметизированную кварцевую трубу пропускался поток аргона высокой чистоты с расходом 15-20 см $3 /$ мин. В кварцевой трубе со стороны входа аргона в температурной зоне $150{ }^{\circ} \mathrm{C}$ была расположена керами- ческая лодочка с серой квалификации ОСЧ. Образующиеся пары серы переносились потоком аргона в высокотемпературную область трубы и там взаимодействовали с поверхностью молибденовой фольги. В результате этого взаимодействия на поверхности молибдена образовывался слой дисульфида молибдена, плотность, морфология и структура которого зависела от температуры синтеза.

Перечень образцов, полученных описанным методом газотранспортного синтеза путем осаждения паров серы на металлических пластинах молибдена при разных температурах в интервале от 300 до $1000{ }^{\circ} \mathrm{C}$, которые в дальнейшем мы исследовали методом рентгеновской дифракции (РД) и сканирующей электронной микроскопии (СЭМ), приведен в табл. 1.

Рентгенофазовый анализ (РФА) полученных образцов проводился на дифрактометре ДРОН-4 с Co $K \alpha$-излучением в режиме пошагового сканирования.

Морфология поверхности образцов исследовалась на сканирующем электронном микроскопе ЈХА-840 ЦКП НО ВГУ.

\section{1. Рентгенофазовый состав образцов} дисульфидов молибдена $\mathrm{MoS}_{2}$, полученных методом осаждения паров серы

на металлических пластинах молибдена

в различных технологических условиях

В табл. 2 приведены результаты РФА одной из металлических пластин Мо, на которых произво- 
Таблица 1. Образцы сульфидов молибдена в системе Mo-S, полученные осаждением паров серы на металлических пластинах молибдена при разных температурах

[Table 1. Samples of molybdenum sulfides in the Mo-S system obtained by depositing sulfur vapors on molybdenum metal plates at different temperatures]

\begin{tabular}{|c|c|}
\hline $\begin{array}{c}\text { Номер образца } \\
\text { [Sample number] }\end{array}$ & $\begin{array}{c}\text { Температура получения сульфидов } \\
\text { на пластинах металлического молибдена } \\
\text { [Sulphides obtaining temperature on molybdenum metal plates] }\end{array}$ \\
\hline 1 & $\begin{array}{c}\text { Мо пластина (комн. температура) } \\
\text { [Mo plate (room temperature) }]\end{array}$ \\
\hline 2 & Mo $+\mathrm{S} \mathrm{300}{ }^{\circ} \mathrm{C}$ \\
\hline 3 & $\mathrm{Mo}+\mathrm{S} 800^{\circ} \mathrm{C}$ \\
\hline 4 & $\mathrm{Mo}+\mathrm{S} 900^{\circ} \mathrm{C}$ \\
\hline 5 & $\mathrm{Mo}+\mathrm{S} 1000^{\circ} \mathrm{C}$ \\
\hline
\end{tabular}

Таблица 2. Значения межплоскостных расстояний $d(\AA)$ и относительных интенсивностей дифракционных линий образца металлической пластины Мо (образец 1)

[Table 2. The values of the interplanar distances $d(\AA)$ and the relative intensities of the diffraction lines of the sample of the metallic Mo plate (sample 1)]

\begin{tabular}{|c|c|c|c|c|c|c|}
\hline $\begin{array}{c}\text { № } \\
{[\text { No.] }}\end{array}$ & $\begin{array}{c}\text { Угол } 2 \theta^{\circ} \\
\text { [Angle } 2 \theta^{\circ} \text { ] }\end{array}$ & $\begin{array}{c}\text { Полуширина } \\
\text { [Semi-wide] }\end{array}$ & $\begin{array}{c}\text { Межплоскостное } \\
\text { расстояние, } d(\AA) \\
{[\text { Interplanar }} \\
\text { spacings, } d(\AA)]\end{array}$ & $\begin{array}{c}\text { Интенсив- } \\
\text { ность. I, \% } \\
\text { [Relative } \\
\text { intensities } I, \% \text { ] }\end{array}$ & $\begin{array}{l}\text { Mo d }(\AA)(00- \\
004-0809)[5] \\
{[\operatorname{Mo~} d(\AA)(00-} \\
004-0809)[5]]\end{array}$ & $\begin{array}{c}, \% \\
(\mathrm{hkl})[5] \\
{[\mathrm{I}, \%} \\
(\mathrm{hkl})[5]]\end{array}$ \\
\hline 1 & 31.100 & 1.0800 & 3.3390 & 1.36 & & \\
\hline 2 & 47.300 & 0.4270 & 2.2314 & 2.59 & 2.225 & $100(110)$ \\
\hline 3 & 61.950 & 0.3360 & 1.7392 & 3.74 & Мo $K \beta$ & \\
\hline 4 & 69.250 & 0.3780 & 1.5753 & 100.00 & 1.574 & $21(200)$ \\
\hline 5 & 78.200 & 0.2690 & 1.4193 & 1.33 & Mo $K \beta$ & \\
\hline 6 & 88.200 & 0.5020 & 1.2862 & 20.81 & 1.285 & $39(211)$ \\
\hline 7 & 127.950 & 0.9340 & 0.9961 & 1.59 & 0.995 & $17(310)$ \\
\hline
\end{tabular}

дился синтез сульфидов молибдена в парах серы. На рис. 2 приведены дифрактограммы всех образцов, перечисленных в табл. 1, в том числе и дифрактограмма Мо пластины. Анализ данных показывает, что кристаллиты металлической пластины имеют преимущественную ориентацию в направлении [100], поэтому самое интенсивное отражение на дифрактограмме (рис. 2) дают плоскости (200) $d=1.5753 \AA$, перпендикулярные этому направлению, в отличие от порошкового образца международной базы данных, карточка PDF Card 2012 (00-004-0809) [5] с самым интенсивным отражением (110) $d=2.225 \AA$. Результаты практически не изменялись и при отжигах Мо пластин до $1000^{\circ} \mathrm{C}$, соотношение интенсивностей дифракционных линий оставалось прежним.

С учетом этих результатов осуществлялась идентификация отражений всех последующих дифрактограмм от образцов со слоями дисульфида молибдена, сформированными на пластинах молибдена.

Далее в табл. 3-6 приведены значения межплоскостных расстояний $d(\AA)$ и относительных ин- тенсивностей дифракционных линий для образцов, полученных путем осаждения паров серы на металлических пластинах молибдена при разных температурах, список которых приведен в табл. 1. На дифрактограмме образца $\mathrm{Mo}+\mathrm{S}\left(300^{\circ} \mathrm{C}\right)$, полученного при самой низкой температуре $300{ }^{\circ} \mathrm{C}$ сульфидирования пластины молибдена в горячей зоне (рис. 2), все линии принадлежат металлическому Мо, кроме одной очень слабой линии $(d=3.8695 \AA$; $I=1.66 \%$ ), которая может принадлежать одному из многочисленных оксидов молибдена. Но при этом самая интенсивная линия молибдена $d=2.225 \AA$ по данным карточки PDF Card 2012 (00-004-0809) [5] Международной Базы Данных появляется в этом образце в виде слабого отражения $d=2.2314(\AA)$, $I=3.66 \%$ (образец 4), (см. рис. 3 и табл. 3 ). Таким образом, при температуре горячей зоны $300{ }^{\circ} \mathrm{C}$ образования сульфидов молибдена не происходит, а молибденовая пластина остается по-прежнему текстурированной.

Далее в табл. 4 и на рис. 2 представлены результаты рентгенофазового анализа образца $\mathrm{Mo}+\mathrm{S}$ 


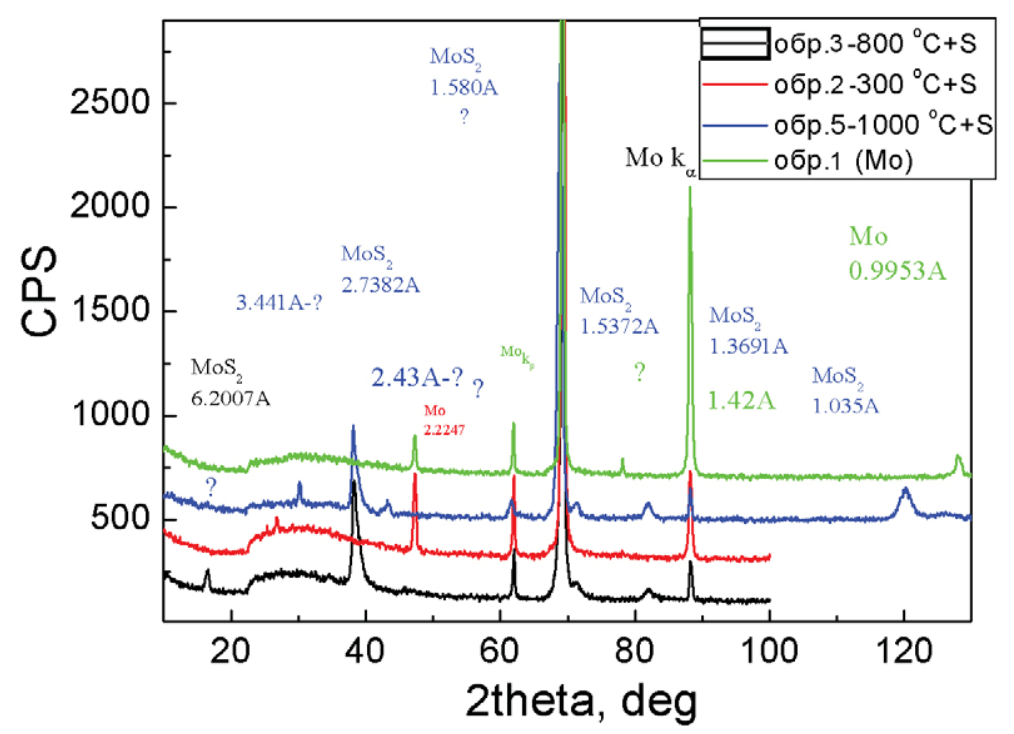

Рис. 2. Дифрактограмма металлической пластины Мо (образец 1) вместе с дифрактограммами образцов Мо+S, полученных в результате сульфидирования пластин молибдена в горячей зоне кварцевой трубы при температу$\operatorname{pax} 300,800$ и $1000^{\circ} \mathrm{C}$

[Fig. 2. Diffractograms of the pure Mo plate and of Mo $+\mathrm{S}$ samples obtained as a result of the sulfidation of molybdenum plates in the hot zone of the quartz tube at temperatures of 300,800 and $\left.1000{ }^{\circ} \mathrm{C}\right]$

Таблица 3. Значение межплоскостных расстояний $d(\AA)$ и относительных интенсивностей дифракционных линий образца, полученного при $300{ }^{\circ} \mathrm{C}$ (образец 2)

[Table 3. The value of the interplanar distances $d(\AA)$ and the relative intensities of the diffraction lines of the sample obtained at $300^{\circ} \mathrm{C}$ (sample 2)]

\begin{tabular}{|c|c|c|c|c|c|c|}
\hline $\begin{array}{c}\text { № } \\
\text { [No.] }\end{array}$ & 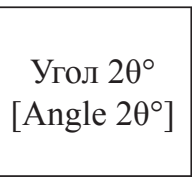 & $\begin{array}{l}\text { Полуширина } \\
\text { [Semi-wide] }\end{array}$ & $\begin{array}{c}\text { Межплоскостное } \\
\text { paccтояние } d(\AA) \\
\text { [Interplanar spacings } \\
d(\AA)]\end{array}$ & \begin{tabular}{|c|} 
Интенсивность \\
$I, \%$ \\
[Relative \\
intensities $I, \%]$ \\
\end{tabular} & $\begin{array}{c}d(\AA) 2012(00- \\
004-0809) \mathrm{Mo} \\
{[d(\AA) 2012(00-} \\
004-0809) \mathrm{Mo}]\end{array}$ & $\begin{array}{c}I, \% ;(\mathrm{hkl}) \mathrm{Mo} \\
{[I, \% ;(\mathrm{hkl}) \mathrm{Mo}]}\end{array}$ \\
\hline 1 & 26.750 & 1.4060 & 3.8695 & 1.66 & $\mathrm{MoO}_{3}$ & \\
\hline 2 & 47.300 & 0.4710 & 2.2314 & 3.66 & Mo 2.225 & $100(110)$ \\
\hline 3 & 62.000 & 0.3630 & 1.7379 & 3.72 & Мо K $\beta$ & \\
\hline 4 & 69.300 & 0.4100 & 1.5743 & 100.00 & Мo 1.574 & $21(200)$ \\
\hline 5 & 88.250 & 0.5250 & 1.2857 & 4.04 & Mo 1.285 & $39(211)$ \\
\hline
\end{tabular}

Таблица 4. Значения межплоскостных расстояний $d(\AA)$ и относительных интенсивностей дифракционных линий образца $\mathrm{Mo}+\mathrm{S} 800{ }^{\circ} \mathrm{C}$, полученного при $800{ }^{\circ} \mathrm{C}$ (образец 3)

[Table 4. The values of the interplanar distances $d(\AA)$ and the relative intensities of the diffraction lines of the sample $\mathrm{Mo}+\mathrm{S} 800{ }^{\circ} \mathrm{C}$, obtained at $800{ }^{\circ} \mathrm{C}$ (sample 3)]

\begin{tabular}{|c|c|c|c|c|c|c|}
\hline $\begin{array}{c}\text { № } \\
\text { [No.] }\end{array}$ & 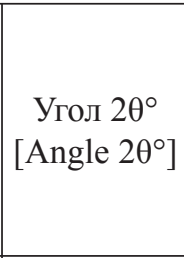 & $\begin{array}{c}\text { Полуширина } \\
\text { [Semi-wide] }\end{array}$ & $\begin{array}{c}\text { Межплоскостное } \\
\text { расстояние } d(\AA) \\
\text { [Interplanar spacings } \\
d(\AA)]\end{array}$ & $\begin{array}{c}\text { Интенсивность } \\
I, \% \\
\text { [Relative } \\
\text { intensities } I, \%]\end{array}$ & $\begin{array}{c}d(\AA) \mathrm{MoS}_{2}(00- \\
006-0097) \\
\mathrm{P}_{3 / 3 m c} \mathrm{mmc}^{-} \\
{\left[d(\AA) \mathrm{MoS}_{2}(00-\right.} \\
006-0097) \\
\left.\mathrm{P}_{3} / \mathrm{mmc}\right]\end{array}$ & $\begin{array}{c}\text { (hkl), }, \% \mathrm{MoS}_{2} \\
(00-006-0097) \\
{[(\mathrm{hkl}), I, \%} \\
\mathrm{MoS}_{2}(00-006- \\
0097)]\end{array}$ \\
\hline 1 & 16.600 & 0.6030 & 6.2007 & 1.68 & $6.150 \mathrm{MoS}_{2}$ & (002) 100 \\
\hline 2 & 38.350 & 0.9330 & 2.7252 & 9.31 & $2.737 \mathrm{MoS}_{2}$ & $(100) 16$ \\
\hline 3 & 62.050 & 0.3490 & 1.7367 & 4.19 & $K \beta \mathrm{Mo}$ & \\
\hline 4 & 69.300 & 0.3950 & 1.5743 & 100.00 & $1.574 \mathrm{Mo}$ & (200) \\
\hline 5 & 88.250 & 0.4680 & 1.2857 & 3.34 & $1.285 \mathrm{Mo}$ & (211) \\
\hline
\end{tabular}


Таблица 4. Значения межплоскостных расстояний $d(\AA)$ и относительных интенсивностей дифракционных линий образца Мо $+\mathrm{S} 800{ }^{\circ} \mathrm{C}$, полученного при $800{ }^{\circ} \mathrm{C}$ (образец 3)

[Table 4. The values of the interplanar distances $d(\AA)$ and the relative intensities of the diffraction lines of the sample Mo $+\mathrm{S} 800{ }^{\circ} \mathrm{C}$, obtained at $800{ }^{\circ} \mathrm{C}$ (sample 3)]

\begin{tabular}{|c|c|c|c|c|c|c|}
\hline $\begin{array}{c}\text { № } \\
\text { [No.] }\end{array}$ & $\begin{array}{c}\text { Угол } 2 \theta^{\circ} \\
\text { [Angle } 2 \theta^{\circ} \text { ] }\end{array}$ & $\begin{array}{c}\text { Полуширина } \\
\text { [Semi-wide] }\end{array}$ & $\begin{array}{c}\text { Межплоскостное } \\
\text { расстояние } d(\AA) \\
\text { [Interplanar } \\
\text { spacings } \\
d(\AA)]\end{array}$ & $\begin{array}{c}\text { Интенсивность } \\
I, \% \\
\text { [Relative } \\
\text { intensities } \\
I, \%]\end{array}$ & \begin{tabular}{|c|}
$d(\AA) \mathrm{MoS}_{2}$ \\
$(00-006-0097)$ \\
$\mathrm{P}_{33} \mathrm{mmc}$ \\
{$\left[d(\AA) \mathrm{MoS}_{2}\right.$} \\
$(00-006-0097)$ \\
$\left.\mathrm{P}_{3} \mathrm{mmc}\right]$ \\
\end{tabular} & $\begin{array}{c}\text { (hkl), }, \%, \mathrm{MoS}_{2} \\
(00-006-0097) \\
{[(\mathrm{hkl}), I, \%} \\
\mathrm{MoS}_{2}(00-006- \\
0097)]\end{array}$ \\
\hline 1 & 16.600 & 0.6030 & 6.2007 & 1.68 & $6.150 \mathrm{MoS}_{2}$ & (002) 100 \\
\hline 2 & 38.350 & 0.9330 & 2.7252 & 9.31 & $2.737 \mathrm{MoS}_{2}$ & (100) 16 \\
\hline 3 & 62.050 & 0.3490 & 1.7367 & 4.19 & $K \beta \mathrm{Mo}$ & \\
\hline 4 & 69.300 & 0.3950 & 1.5743 & 100.00 & $1.574 \mathrm{Mo}$ & (200) \\
\hline 5 & 88.250 & 0.4680 & 1.2857 & 3.34 & $1.285 \mathrm{Mo}$ & (211) \\
\hline
\end{tabular}

$800{ }^{\circ} \mathrm{C}$ (образец 3 ), полученного в результате сульфидирования пластины молибдена в горячей зоне кварцевой трубы при температуре $800{ }^{\circ} \mathrm{C}$. Результаты сравнения табличных данных с карточками международной базы данных PDF Card 2012 (00004-08090) для молибдена [5] и PDF Card 2012 (00-006-0097) для гексагонального сульфида молибдена $\mathrm{MoS}_{2}[6]$ показывают, что из пяти дифракционных линий, полученных на дифрактограмме (рис. 2), две первых линии принадлежат самым интенсивным отражениям гексагональной фазы $\mathrm{MoS}_{2}$ Р6 ${ }_{3}$ mmc с параметрами: $a=3.16 \AA$ и $c=12.295 \AA$.
Три следующие линии принадлежат пластине металлического молибдена, на которой образовался тонкий слой $\mathrm{MoS}_{2}$ при температуре $800{ }^{\circ} \mathrm{C}$ в результате реакции с парами серы. При этом следует отметить полное отсутствие на дифрактограмме самой интенсивной линии металлического Мо (110) с $\boldsymbol{d}=\mathbf{2 . 2 2 5} \AA$ [5], являющееся следствием текстурирования ее структуры.

Далее в табл. 5 представлены результаты рентгенофазового анализа образца $\mathrm{Mo}+\mathrm{S} 900{ }^{\circ} \mathrm{C}$ (образец 4), полученного в результате сульфидирования пластины молибдена в горячей зоне кварцевой тру-

Таблица 5. Значения межплоскостных расстояний $d(\AA)$ и относительных интенсивностей дифракционных линий образца $\mathrm{Mo}+\mathrm{S} 900{ }^{\circ} \mathrm{C}$, полученного при $900{ }^{\circ} \mathrm{C}$ (образец 4)

[Table 5. The values of the interplanar distances $d(\AA)$ and the relative intensities of the diffraction lines of the $\mathrm{Mo}+\mathrm{S}(4) 900{ }^{\circ} \mathrm{C}$ sample obtained at $900{ }^{\circ} \mathrm{C}$ (Sample 4)]

\begin{tabular}{|c|c|c|c|c|c|c|}
\hline $\begin{array}{c}\text { № } \\
{[\text { №.] }}\end{array}$ & 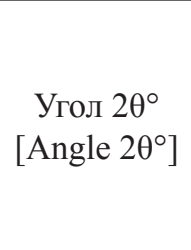 & $\begin{array}{c}\text { Полуширина } \\
\text { [Semi-wide] }\end{array}$ & $\begin{array}{c}\text { Межплоскост- } \\
\text { ное расстояние } \\
d(\AA) \\
{[\text { Interplanar }} \\
\text { spacings } d(\AA)]\end{array}$ & $\begin{array}{c}\text { Интенсивность } \\
I, \% \\
\text { [Relative } \\
\text { intensities } \\
\text { I, \%] }\end{array}$ & $\begin{array}{c}d(\AA) \mathrm{MoS}_{2} \\
\text { ромбоэдр. } \\
(00-017-0744) \\
{\left[d(\AA) \mathrm{MoS}_{2}\right.} \\
\text { rhombohedral } \\
(00-017-0744)]\end{array}$ & $\begin{array}{c}d(\AA) \mathrm{MoO}_{3} \\
(00-005-508) \\
{\left[d(\AA) \mathrm{MoO}_{3}\right.} \\
(00-005-508)]\end{array}$ \\
\hline 1 & 27.250 & 0.6510 & 3.7998 & 4.52 & & 3.810 \\
\hline 2 & 30.250 & 0.3580 & 3.4305 & 100.00 & & 3.463 \\
\hline 3 & 43.200 & 0.5090 & 2.4315 & 14.48 & 2.34 & \\
\hline 4 & 58.250 & 0.3560 & 1.8391 & 3.89 & 1.889 & \\
\hline 5 & 62.500 & 0.5630 & 1.7254 & 11.92 & 1.755 & \\
\hline 6 & 63.050 & 0.4060 & 1.7119 & 23.52 & & 1.733 \\
\hline 7 & 69.300 & 0.3470 & 1.5743 & 42.88 & 1.581 & \\
\hline 8 & 71.400 & 0.6130 & 1.5339 & 6.89 & 1.529 & \\
\hline 9 & 79.200 & 0.4650 & 1.4043 & 4.17 & 1.403 & \\
\hline 10 & 94.800 & 0.5970 & 1.2160 & 4.96 & 1.214 & \\
\hline 11 & 103.300 & 0.4920 & 1.1414 & 4.25 & 1.179 & \\
\hline 12 & 111.200 & 0.6770 & 1.0848 & 4.11 & 1.099 & \\
\hline
\end{tabular}


бы при $900{ }^{\circ} \mathrm{C}$. Результаты сравнения табличных данных с карточками международной базы данных PDF Card 2012 (00-017-0744) для ромбоэдрического сульфида молибдена $\mathrm{MoS}_{2}$ [7] и PDF Card 2012 (00005-508) для триоксида молибдена $\mathrm{MoO}_{3}$ показывают, что из 12 дифракционных линий, полученных на дифрактограмме, 9 линий принадлежат отражениям ромбоэдрической фазы $\mathrm{MoS}_{2}$ с параметрами: $a=3.16 \AA$ и $c=18.33 \AA$, пространственная группа $\mathrm{R} 3 \mathrm{~m}$. Однако остальные три отражения, в числе которых самая интенсивная линия $d=3.4305(\AA)$, принадлежат одной из многочисленных модификаций орторомбического триоксида молибдена $\mathrm{MoO}_{3}$ [8]. Таким образом, при температуре $900{ }^{\circ} \mathrm{C}$ наряду с триоксидом молибдена $\mathrm{MoO}_{3}$ образуется ромбоэдрическая модификация $\mathrm{MoS}_{2}$, отличающаяся от гексагональной фазы большим параметром $c$.

И, наконец, в табл. 6 и на том же рис. 2 представлены результаты рентгенофазового анализа образца Мо $+\mathrm{S} 1000{ }^{\circ} \mathrm{C}$ (образец 5), полученного в результате сульфидирования пластины молибдена в горячей зоне кварцевой трубы при самой высокой температуре $1000^{\circ} \mathrm{C}$. Результаты сравнения табличных данных с карточками международной базы данных для молибдена [5] и для ромбоэдрического дисульфида молибдена $\mathrm{MoS}_{2}$ [7] показывают, что из 8 дифракционных линий, полученных на дифрактограмме (рис. 2), шесть линий принадлежат отражениям ромбоэдрической фазы $\mathrm{MoS}_{2}$. И только 2 слабых линии: $d=3.441 \AA, d=2.431 \AA$, принадлежат одной из многочисленных модификаций триоксида молибдена $\mathrm{MoO}_{3}$. Таким образом, при температуре $1000{ }^{\circ} \mathrm{C}$ образуется ромбоэдрическая модификация $\mathrm{MoS}_{2}$. Отсутствие при этом самого интенсивного отражения (003) этой фазы с $d=6.090 \AA$ может быть вызвано преимущественной ориентацией нанокристаллов ромбоэдрической фазы вдоль направления [110].

Таким образом, результаты, представленные на рис. 2 с совмещенными дифрактограммами образцов, полученных в результате сульфидирования пластин молибдена в горячей зоне кварцевой трубы при различных температурах: 300,800 , $1000{ }^{\circ} \mathrm{C}$, в сравнении с дифрактограммой чистой пластины Мо, наглядно показывают, что при разных высоких температурах 800 и $1000^{\circ} \mathrm{C}$ на пластинах молибдена образуются сульфиды молибдена разных модификаций: гексагональная $\mathrm{P} 6_{3} / \mathrm{mmc}$ при $800{ }^{\circ} \mathrm{C}$ и ромбоэдрическая (тригональная) $\mathrm{R} 3 \mathrm{~m}$ при $1000{ }^{\circ} \mathrm{C}$.

\section{2. Сканирующая электронная микроскопия образцов сульфидов молибдена $\mathrm{MoS}_{2}$, полученных на металлических пластинах молибдена при различных температурах}

В этом разделе последовательно представлены результаты сканирующей электронной микроскопии (СЭМ) пластины металлического молибдена Мо, на котором синтезировались сульфиды молибдена газотранспорным осаждением паров серы, и образцов сульфидов молибдена $\mathrm{MoS}_{2}$, полученных на металлических пластинах молибдена при различных температурах.

На рис. 3 слева представлены результаты СЭМ пластины металлического молибдена Мо, на котором синтезировались сульфиды молибдена газотранспорным осаждением паров серы, которые показывают на отсутствие явно выраженных микродефектов поверхности пластины. Тем не менее, на

Таблица 6 Значение межплоскостных расстояний $d(\AA ̊)$ и относительных интенсивностей дифракционных линий образца Мо $+\mathrm{S} 1000{ }^{\circ} \mathrm{C}$, полученного при $1000{ }^{\circ} \mathrm{C}$ (образец 5)

[Table 6. The value of the interplanar distances $d(\AA)$ and the relative intensities of the diffraction lines of the sample Mo $+\mathrm{S} 1000{ }^{\circ} \mathrm{C}$, obtained at $1000{ }^{\circ} \mathrm{C}$ (sample 5)]

\begin{tabular}{|c|c|c|c|c|c|c|}
\hline $\begin{array}{c}\text { № } \\
{[\text { No.] }}\end{array}$ & $\begin{array}{c}\text { Угол } 2 \theta^{\circ} \\
\text { [Angle } 2 \theta^{\circ} \text { ] }\end{array}$ & $\begin{array}{c}\text { Полуширина } \\
\text { [Semi-wide] }\end{array}$ & $\begin{array}{c}\text { Межплоскост- } \\
\text { ное расстояние } \\
d(\AA) \\
\text { [Interplanar } \\
\text { spacings } d(\AA)]\end{array}$ & $\begin{array}{c}\text { Интенсивность } \\
I, \% \\
\text { [Relative } \\
\text { intensities } \\
I, \%] \\
\end{array}$ & $\begin{array}{c}d \mathrm{MoS}_{2} \text { ромбоэдр. } \\
(00-017-0744) \\
{\left[d \mathrm{MoS}_{2}\right.} \\
\text { rhombohedral } \\
(00-017-0744)] \\
\end{array}$ & $\begin{array}{c}\text { (hkl), I, \% (00- } \\
017-0744) \\
{[(\mathrm{hkl}), I, \%(00-} \\
017-0744)]\end{array}$ \\
\hline 1 & 30.150 & 0.5300 & 3.4416 & 6.57 & $\mathrm{MoO}_{3}$ & \\
\hline 2 & 38.200 & 0.8800 & 2.7355 & 19.02 & $2.710^{3}$ & (101) 70 \\
\hline 3 & 43.200 & 0.3110 & 2.4315 & 2.87 & $\mathrm{MoO}_{3}$ & \\
\hline 4 & 61.650 & 0.7270 & 1.7468 & 4.24 & 1.755 & (018) 30 \\
\hline 5 & 68.850 & 0.8030 & 1.5833 & 100.00 & 1.581 & (110) 70 \\
\hline 6 & 82.100 & 1.2000 & 1.3630 & 3.69 & 1.363 & (021) 20 \\
\hline 7 & 88.250 & 0.4070 & 1.2857 & 6.98 & 1.283 & $(205) 10$ \\
\hline 8 & 120.200 & 1.8680 & 1.0325 & 7.39 & 1.031 & $(211) 5$ \\
\hline
\end{tabular}


изображении просматриваются наклонно-поперечные эквидистантные полосы, свидетельствующие о возможной текстуре образца, которую мы и обнаружили на рентгеновской дифракции этих пластин. Результаты микроанализа с точностью до 1.84 \% показали отсутствие заметного количества примесей в металлической пластине молибдена.

Далее на том же рис. 3 справа представлены результаты СЭМ образца гексагонального дисульфида молибдена $\mathrm{MoS}_{2}$, полученного газотранспорным осаждением паров серы на металлической пластине молибдена при температуре $800{ }^{\circ} \mathrm{C}$. Микрофотография этого образца показывает на изменение морфологии поверхности металлической пласти-

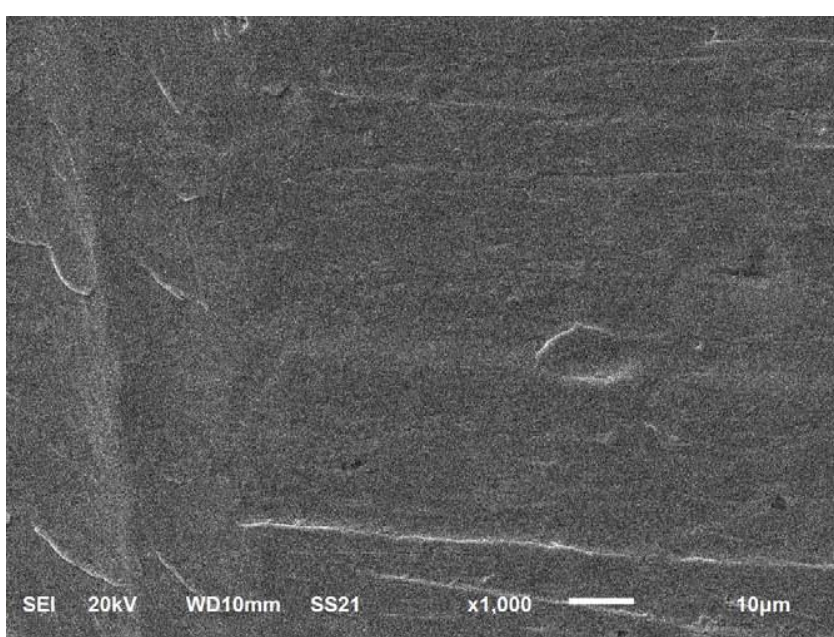

ны в результате сульфидирования ее поверхности и наслаивания сульфида молибдена $\mathrm{MoS}_{2}$ гексагональной модификации. На микрофотографии этого образца просматриваются треугольные и треугольноподобные домены, свидетельствующие о гексагональной структуре полученных дисульфидных слоев, которые легко обнаруживаются в однослойных структурах $\mathrm{MoS}_{2}$ [9].

К сожалению, метод микроанализа не позволяет обнаружить наличие серы в образце, так как гораздо более интенсивная Mo $L \alpha ́$ - линия молибдена накладываеся на $\mathrm{S} K \dot{\alpha}-$ и $\mathrm{S} K \beta$ - линии серы.

И, наконец, на рис. 4 представлены результаты сканирующей электронной микроскопии дисуль-

Рис. 3. Микрофотографии СЭМ поверхности пластины металлического молибдена Мо (слева) и гексагонального дисульфида молибдена $\mathrm{MoS}_{2}$ (справа) полученного на металлической пластине молибдена при температуре синтеза $800{ }^{\circ} \mathrm{C}$

[Fig. 3. SEM microphotographs of the molybdenum metal Mo plate surface (left) and hexagonal molybdenum disulfide $\mathrm{MoS}_{2}$ (right) obtained on a metal plate of molybdenum at a synthesis temperature of $800^{\circ} \mathrm{C}$ ]
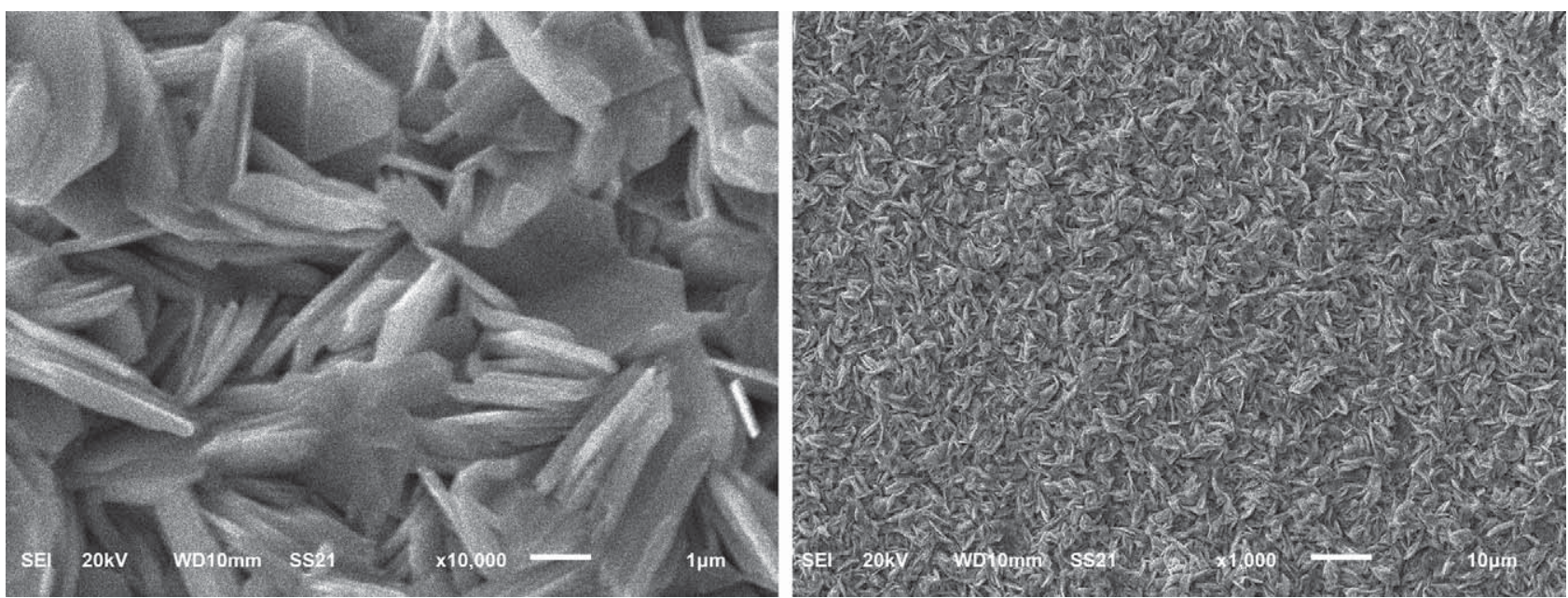

Pис. 4. Микрофотографии СЭМ ромбоэдрического дисульфида молибдена $\mathrm{MoS}_{2}$ полученного на металлической пластине молибдена при температуре синтеза $1000^{\circ} \mathrm{C}$

[Fig. 4. SEM microphotographs of rhombohedral molybdenum disulfide $\mathrm{MoS}_{2}$ obtained on a molybdenum metal plate at a synthesis temperature of $\left.1000^{\circ} \mathrm{C}\right]$ 
фида молибдена $\mathrm{MoS}_{2}$, полученного на металлической пластине молибдена при температуре $1000^{\circ} \mathrm{C}$. Они показывают очевидные изменения морфологии поверхности металлической пластины в результате роста на ее поверхности микрокристаллов дисульфида молибдена $\mathrm{MoS}_{2}$ ромбоэдрической модификации R3m.

Таким образом, результаты исследования методом СЭМ образцов сульфидов молибдена $\mathrm{MoS}_{2}$ (рис. 3 и рис. 4), полученных на металлических пластинах молибдена при различных температурах, показывают, что только при температуре $1000{ }^{\circ} \mathrm{C}$ происходит формирование микрокристаллов $\mathrm{MoS}_{2}$ с огранкой, соответствующей ромбоэдрической (тригональной) фазе R3m.

\section{ЗАКЛЮЧЕНИЕ}

Проведенные исследования методами РФА и СЭМ процесса формирования сульфидов молибдена при переносе паров серы на металлические пластины молибдена при различных температурах синтеза в горячей зоне кварцевого реактора показывают, что при высоких температурах синтеза в интервале $800-1000{ }^{\circ} \mathrm{C}$ на пластинах молибдена образуются дисульфиды молибдена различных модификаций/политипов: гексагональной $\mathrm{P} 6_{3} / \mathrm{mmc}$ при $800{ }^{\circ} \mathrm{C}$ и ромбоэдрической (тригональной) $\mathrm{R} 3 \mathrm{~m}$ при $1000^{\circ} \mathrm{C}$.

Формирование микрокристаллов $\mathrm{MoS}_{2}$ с огранкой, соответствующей ромбоэдрической фазе R3m в преимущественном направлении [110], происходит при температуре $1000^{\circ} \mathrm{C}$.
Работа выполнена при поддержке Минобрнауки России в рамках государственного задания ВУЗам в сфере научной деятельности на 2017-2019 годы. Проекты № 3.6263.2017/ВУ и № 16.8158.2017/8.9.

\section{СПИСОК ЛИТЕРАТУРЫ}

1. Иртегов Ю. А., Яворовский Н. А // Известия Высших Учебных Заведений. Физика, 2012, т. 55, № 5/2, c. $140-145$.

2. Bhupendra Mor, Madhvi Dave, Vidhi Raval // International Journal on Recent and Innovation Trends in Computing and Communication, 2014, vol. 2, № 11, pp. 35783582. Доступна на http://www.ijritcc.org/download/1418296204.pdf

3. Мишина Е. Д., Шерстюк Н. Э., Шестакова А. П, Лавров С. Д., Семин А. С. Сигов С. В., Митиоглу А., Ангел С., Кулюк Л. // ФТП, 2015, т. 49, вып. 6, с. 810-816. DOI: $10.1134 / \mathrm{S} 1063782615060159$

4. Шестакова А. П., Лавров С. Д., Мишина Е. Д. Материаль Международной научно-технической конферениии. 1 - 5 декабря 2015 г., Москва, INTERMATIC, часть 1, 2015, МИРЭА, с. 107-110.

5. CPDS - International Centre for Diffraction Data. 2012, № 00-004-0809.

6. CPDS - International Centre for Diffraction Data. 2012, № 00-006-0097.

7. CPDS - International Centre for Diffraction Data. 2012, № 00-017-0744.

8. CPDS - International Centre for Diffraction Data. 2012, № 00-005-508 $\mathrm{MoO}_{3}$.

9. Qingqing Ji, Yanfeng Zhang, Teng Gao, Zhang Yu, Donglin Ma, Mengxi Liu, Yubin Chen, Xiaofen Qiao, PingHeng Tan, Min Kan, Ji Feng, Qiang Sun, Zhongfan Liu // Nano Letters, 2013, vol. 13, № 8, pp. 3870-3877. DOI: $10.1021 / \mathrm{nl} 401938 \mathrm{t}$

\title{
SPECIFICS OF THE FORMATION OF THIN LAYERS OF MOLYBDENUM DISULFIDE $\mathrm{MOS}_{2}$ ON METAL MOLYBDENUM AT DIFFERENT TEMPERATURES
}

\author{
(c) 2018 E. P. Domashevskaya, S. A. Ivkov, Al Khaylanani Hasan Ismail Dambos, Radam Ali Obaid \\ Radam, S. V. Ryabtsev
}

Voronezh State University, 1 Universitetskaya pl., 394018 Voronezh, Russia

e-mail: ftt@phys.vsu.ru

Received 02.02.2018

\begin{abstract}
MoS, is classified as a transition metal dichalcogenide. They crystallize as layered structures of various modifications. The strong anisotropy of the crystal structure of these compounds leads to the easy splitting of the layers along the cleavage planes perpendicular to the parameter $c$ of the crystal. Therefore, the physical properties of these compounds are very anisotropic.
\end{abstract}


The aim of the paper is to show the influence of temperature on the phase composition and crystal structure of thin layers formed on metal molybdenum plates during gas transfer of sulphur vapours to the hot zone of the reactor. Molybdenum disulphides were produced in a sealed quartz tube, the middle part of which was heated to the necessary temperatures in the range of $300-1000{ }^{\circ} \mathrm{C}$. In this high-temperature part of the quartz tube, molybdenum foil was placed, which was purified of oxides in advance. In the quartz tube, from the side of the entrance of the argon gas, in the temperature zone of $150{ }^{\circ} \mathrm{C}$, there was a ceramic boat with sulphur. The resulting sulphur vapours were transferred by a flow of argon to the high-temperature region of the tube and there interacted with the surface of the molybdenum plate. As a result of this interaction, a layer of molybdenum disulphides was formed on the molybdenum surface, the density morphology and the structure of which depended on the synthesis temperature.

The results of the X-ray diffraction and scanning electron microscopy samples investigations of molybdenum disulphides $\mathrm{MoS}_{2}$ obtained on metal Mo plates at different temperatures show that at high temperatures of gas transport synthesis in the range $800-1000{ }^{\circ} \mathrm{C}$, molybdenum disulphides of various modifications/polytypes are formed: the polytype of $2 \mathrm{H}$ hexagonal syngony $\mathrm{P}_{3} / \mathrm{mmc}$ at 800 ${ }^{\circ} \mathrm{C}$ and the polytype $3 \mathrm{R}$ of rhombohedral (trigonal) syngony $\mathrm{R} 3 \mathrm{~m}$ at $1000{ }^{\circ} \mathrm{C}$.

At the temperature of $1000{ }^{\circ} \mathrm{C}, \mathrm{MoS}_{2}$ microcrystals with a facet corresponding to the rhombohedral phase of $\mathrm{R} 3 \mathrm{~m}$ are formed.

Keywords: two-temperature synthesis, metallic molybdenum, disulfide molybdenum, polytypes, hexagonal modification, rhombohedral modification.

DOI: https://doi.org/10.17308/kcmf.2018.20/477

\section{ACKNOWLEDGMENTS}

The work was supported by the Ministry of Education and Science of the Russian Federation in the framework of the state order to higher education institutions in the sphere of scientific research for years 2017 - -2019. Projects № 3.6263.2017/VU and № 16.8158.2017/8.9.

\section{REFERENCES}

1. Irtegov Yu. A., Yavorovsky N. A. News of Higher Educational Institutions. Physics, 2012, vol. 55, no. 5/2, pp. 140-145. (in Russ.)

2. Bhupendra Mor, Madhvi Dave, Vidhi Raval. International Journal on Recent and Innovation Trends in Computing and Communication ISSN: 2321-8169, 2014, vol. 2, no. 11, p. 3578-3582. Available at: http://www.ijritcc.org/ download/1418296204.pdf

3. Mishina E. D., Sherstyuk N. E., Shestakova A. P., Lavrov S. D., Semin S. Sigov S. V., Mitioglu A., Angel S.,
Kulyuk L. Semiconductors, 2015, vol. 49, no. 6, pp. 791796. DOI: $10.1134 / \mathrm{S} 1063782615060159$

4. Shestakova A. P., Lavrov S. D., Mishina E. D. Materialy Mezhdunarodnoi nauchno-tekhnicheskoi konferentsii [Proc. of the International Scientific and Technical Conference. December 1-5, 2015 Moscow, INTERMATIC, part 1]. 2015, MIREA, pp. 107-110.

5. CPDS - International Center for Diffraction Data. 2012, no. 00-004-0809.

6. CPDS - International Center for Diffraction Data. 2012, no. 00-006-0097.

7. CPDS - International Center for Diffraction Data. 2012, no. 00-017-0744.

8. CPDS - International Center for Diffraction Data. 2012, no. 00-005-508 $\mathrm{MoO}_{3}$.

9. Qingqing Ji, Yanfeng Zhang, Teng Gao, Zhang Yu, Donglin Ma, Mengxi Liu, Yubin Chen, Xiaofen Qiao, PingHeng Tan, Min Kan, Ji Feng, Qiang Sun, Zhongfan Liu. Nano Letters, 2013, vol .13, no. 8, pp. 3870-3877. DOI: $10.1021 / \mathrm{nl} 401938 \mathrm{t}$
Домашевская Эвелина Павловна - д. ф.-м. н., профессор, зав. кафедрой физики твердого тела и наноструктур, Воронежский государственный университет; тел.: +7(473) 2208363, e-mail: ftt@phys.vsu.ru

Ивков Сергей Александрович - аспирант кафедры физики твердого тела и наноструктур, Воронежский государственный университет
Evelina P. Domashevskaya - Dr. Sci. (Phys.-Math.), Full Professor, Head of Solid State Physic and Nanostructures Department, Voronezh State University; tel.: +7(473) 2208363; e-mail: ftt@phys.vsu.ru

Sergey A. Ivkov - post-graduate student of the Department of Solid State Physics and Nanostructures Department, Voronezh State University 
Аль Хайлани Хасан Исмаил Дамбос - аспирант кафедры физики твердого тела и наноструктур, Воронежский государственный университет

Радам Али Обайд Радам - магистр кафедры физики твердого тела и наноструктур, Воронежский государственный университет

Рябиев Станислав Викторович-д. ф.-м. н., старший научный сотрудник кафедры физики твердого тела и наноструктур, Воронежский государственный университет; тел.: +7(951) 5609911, e-mail: ryabtsev@phys.vsu. $\mathrm{ru}$
Al Khaylanani Hasan Ismail Dambos - post-graduate student of the Department of Solid State Physics and Nanostructures Department, Voronezh State University

Radam Ali Obaid Radam - Master of Solid State Physics and Nanostructures, Voronezh State University

Stanislav V. Ryabtsev - Dr. Sci. (Phys.-Math.), Senior Researcher of the Solid State Physics and Nanostructures Department, Voronezh State University; tel.: +7(951) 5609911, e-mail: ryabtsev@phys.vsu.ru 